\title{
Advantages of suspension structures under seismic effects on the example of the water tank
}

\author{
Taliat Azizov ${ }^{1}$, Nadzieja Jurkowska, ${ }^{2,}$, Oleksiy Melnik ${ }^{1}$ \\ ${ }^{1}$ Pavlo Tychyna Uman State Pedagogical University, Uman, Ukraine \\ 2 Tadeusz Kosciuszko Cracow University of Technology, Krakow, Poland
}

\begin{abstract}
The paper presents the advantages of suspension buildings and structures in comparison with the traditional buildings. It has been demonstrated, that during an earthquake the strains in the support structures of such buildings and structures are significantly reduced compared to the strains in traditional cantilever buildings. The advantage of the suspension structures is shown by the example of a water tower with a tank of a capacity of $50 \mathrm{~m}^{3}$. Various schemes of the considered construction are given: the construction freely suspended on the bearing frame, the construction with the suspended foundation (prototype). These schemes are compared with the scheme of the cantilever structure. It is proved that the dynamic forces arising from the ground oscillation in the suspended structure are less than the forces in the cantilever structure. The strains depend on the frequency and amplitude of the ground vibrations. The scheme of the forces' adjustment by means of springs (dampers) is given. It is illustrated that by changing the flexural stiffness of the bearing frame, changing the stiffness of the damper, it is possible to adjust the frequency of oscillations and forces in the suspension building or structure.
\end{abstract}

Keywords: suspension structure, dynamic forces, oscillation frequency

\section{The problem statement}

Numerous solutions are applied to protect buildings and structures from earthquakes [1-6]. They include methods for solving certain schemes of bearing structures, various damping devices, reducing the amplitude of oscillations, etc.

The authors of this article have demonstrated [1-3] that in suspension buildings and structures the dynamic forces are much smaller compared to the efforts in traditional buildings during ground vibrations. It was also shown that under certain conditions the advantage of suspension buildings and structures can be minimal. This factor can be negative in the implementation of such constructive systems. Moreover, earlier the constructive

\footnotetext{
* Corresponding author: nadzieja.jurkowska@pk.edu.pl
} 
schemes with suspended foundations were also proposed [7]. However, such constructive schemes for some reason did not find the practical application. The reasons for the refusal of such a decision have not been clarified. As shown by the study of the authors of this article, the strains in suspension structures are significantly reduced, but there may be large displacements in the supporting structures, which is also not acceptable.

In order to find all advantages and disadvantages of the proposed structural systems they should be compared. Besides, the study of additional structural measures that would reduce displacements of bearing structures due to the ground vibration, would also reveal the benefits and disadvantages of suspension buildings and structures.

With regard to the aforesaid, the purpose of this paper is to investigate the proposed suspension structure. The tasks consist in:

- comparison of dynamic forces of suspension buildings with the strains in the cantilever buildings and buildings with suspended foundations, during the ground vibration;

- analysis of influence of the amplitude and frequency of oscillations of the base on the dynamic forces in these types of buildings;

- analysis of the impact of the horizontal stiffness of the bearing structures on the forces in different types of load bearing structural schemes.

\section{Dynamic schemes of buildings and structures}

Most clearly and simply the difference in design schemes can be seen in the case of a onemass scheme of a building or structure. Let us consider, for example, the design of the Rozhnovsky water tower with a tank of 50 cubic meters. The mark of such a tower is VBR 50/15. The scheme of the water tower is shown in Figure 1.

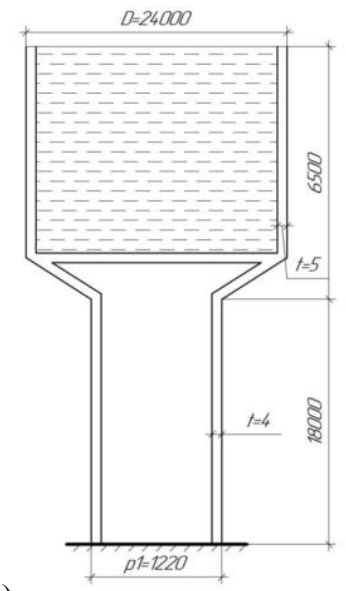

a)

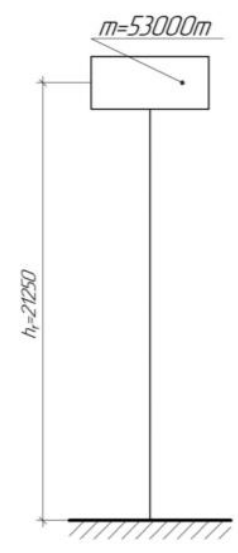

b)

Fig. 1. Design of the Rozhnovsky water tower $50 \mathrm{~m}^{3}$ of water:

a) structural scheme; b) dynamic design scheme

The weight of the tank together with water is $53000 \mathrm{~kg}$. The supporting structure (column) for the tank is a metal pipe with a diameter of $1220 \mathrm{~mm}$ with a wall thickness of $4 \mathrm{~mm}$. According to the Figure 1, the dynamic design scheme is a vertical cantilever with a concentrated mass at on the top.

In order to create the same structural conditions for the tank in the proposed suspension structure (see Figure 2) it is located at the same height as the prototype tower in Figure 1. 
a)

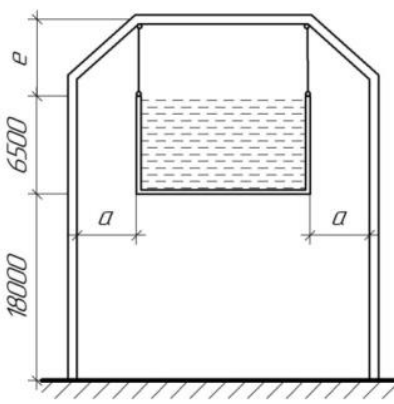

Fig. 2. Design of a water tower with the suspended tank a) structural scheme; b) dynamic design scheme

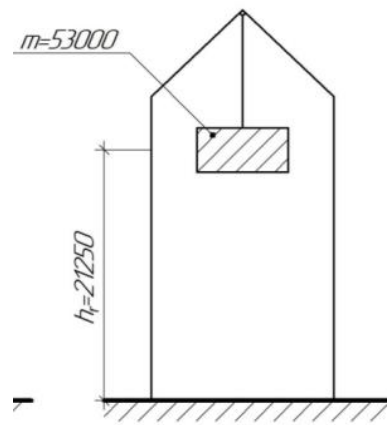

b)

The supporting frame for the suspension structure can be made of pipes with a diameter of $150 \mathrm{~mm}$. Preliminary cross sections of the supporting structures of the frame can be easily selected by the calculation for the static load. These sections can be adjusted after dynamic calculation. The gap between the water tower tank and the supporting structures is indicated by $a$ in Figure 2. The lengthof the tank suspension thread may also vary. The dynamic forces during the ground vibrations caused by the earthquake also depend on this length.

The value of the horizontal stiffness of the bearing frame in Figure 2 can be easily changed by adding or removing bracing and inclined bars between the supporting columns of the frame. Thus, the horizontal stiffness of such a frame can either be much smaller or much greater than the horizontal stiffness of the existing water tower, the scheme of which is shown in Figure 1.

For the analysis of the dynamic forces in different structures of the water tower the stiffness will be accepted equal for all the variants. By knowing the difference in efforts, it's possible to choose the optimal value of the horizontal stiffness for the bearing frame of the suspended tank. Then the frame of the bearing frame of the tank should be constructed. Its stiffness will be approximately equal to the optimal stiffness $k_{x}$ found from the dynamic calculations.

The dynamic calculation schemes for different options are shown in Figure 3.

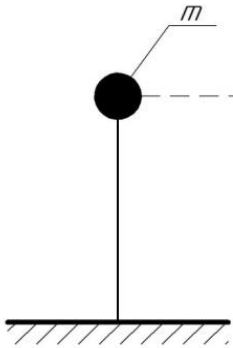

a)

b)

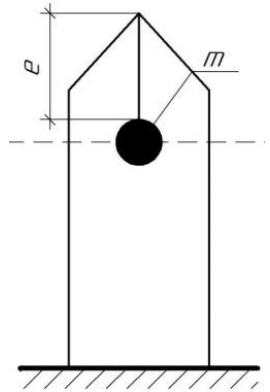

c)

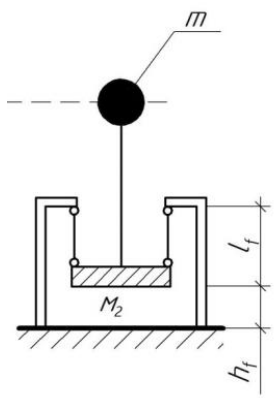

Fig. 3. The dynamic design scheme of the water tower: a) the cantilever existing scheme;

b) the proposed suspension structure; c) the structure with the suspended foundation as proposed [8] 
In all variants, the mass $m$ of the water tank is the same and equal to $53000 \mathrm{~kg}$. The height of the mass and the horizontal stiffness of the supporting structure are also accepted equal in all variants. In the variant with the suspended foundation according to the proposal [7], the mass $M_{2}$ of the foundation is equal to $6000 \mathrm{~kg}$ (approximately reinforced concrete foundation slab in terms of $2 \times 2 \mathrm{~m}$ and $600 \mathrm{~mm}$ thick).

\section{Analysis of dynamic forces in various design schemes}

Calculations of all design schemes for the ground vibrations are conducted by the methods of theoretical mechanics. The design scheme with a suspended tank is calculated by the technique proposed previously by the authors [1-3]. The law of oscillation of the base in all variants is accepted as:

$$
x_{0}=a \cdot \sin (p \cdot t)
$$

where $a$ is the amplitude of oscillations;

$p$ is the frequency of the ground vibrations;

$t$ is time.

Varying in the values of the amplitude and frequency of oscillations of the base was carried out for the following reasons. It is known [4, 7, 8] that for a certain intensity of the earthquake there are values of the maximum amplitude $a_{\max }$ and the maximum acceleration $W_{\max }$. One of the options for setting the amplitude and frequency by the formula (1) was to determine the circular frequency $p$ corresponding to the ultimate acceleration at the maximum amplitude. The acceleration of the ground vibrations is determined from the formula (1) by the expression:

$$
W=\ddot{x}=-a \cdot p^{2} \sin (p \cdot t)
$$

Considering this, the frequency corresponding to the maximum acceleration value $W$, by the formula (2) is determined by the expression:

$$
p=\sqrt{\frac{W}{a}}
$$

First the maximum values of acceleration and amplitude were calculated by the formula (3). Then the variants were compared, and the necessary oscillation frequency corresponding to the maximum acceleration and amplitude values were determined. The Table 1 provides data on this comparison. The maximum value of the vibration amplitude $a=0.36 \mathrm{~m}$ is taken from the data $[7,8]$ as the average value for an earthquake with magnitude 9.0 by the Richter scale (value $0.24-0.48 \mathrm{~m}$ ). The maximum acceleration of the ground vibration is $3.6 \mathrm{~m} / \mathrm{s}^{2}$. It should be noted that this value of the maximum amplitude is taken with a significant margin, since by the seismic intensity scale MSK-64 [4] for the 9.0 earthquake, the amplitude of oscillations is $0.081-0.16 \mathrm{~m}$ for the acceleration of $2-4 \mathrm{~m} / \mathrm{s}^{2}$.

In the Table $1 k_{x}$ is the stiffness coefficient, $a$ is the amplitude, $p$ is the circular frequency, $\mathrm{A}$ is the suspended tank, B is the cantilever structure, $\mathrm{C}$ is the suspended foundation,

For the visual representation, the graphs of dependence of the maximum horizontal dynamic force $F_{\max }[\mathrm{N}]$ on the stiffness coefficient of the bearing frame $k_{x}[\mathrm{~N} / \mathrm{m}]$ for different amplitudes $a$ and circular frequencies $p$ are presented in Figures 4-7.

For the suspended foundation the forces significantly exceed the strains of both in cantilever and suspension structures. That's why the data for the suspended foundation are not given. This fact indicates that such a method for seismic protection of buildings and structures is completely unacceptable. Presumably, that is the reason why it has not been extended for practice. 
Table 1. Comparison of the maximum dynamic forces

for different versions of the water tower structures

\begin{tabular}{|c|c|c|c|c|c|c|c|c|c|}
\hline \multirow{2}{*}{ № } & \multirow{2}{*}{$k_{x},[\mathrm{~N} / \mathrm{m}]$} & \multirow{2}{*}{$a,[\mathrm{~m}]$} & \multirow{2}{*}{$\begin{array}{c}p, \\
{[\mathrm{rad} / \mathrm{s}]}\end{array}$} & \multicolumn{3}{|c|}{$F_{\max },[\mathrm{N}]$} & \multicolumn{3}{|c|}{$X_{\max },[\mathrm{m}]$} \\
\hline & & & & A & $\mathrm{B}$ & $\mathrm{C}$ & A & B & $\mathrm{C}$ \\
\hline 1 & \multirow[t]{4}{*}{10000} & 0.36 & 3.16 & 30230 & 18550 & 60270 & 3.023 & 1.855 & 6.027 \\
\hline 2 & & 0.18 & 4.47 & 20520 & 11980 & 18550 & 2.052 & 1.198 & 1.855 \\
\hline 3 & & 0.09 & 6.33 & 14120 & 8087 & 10910 & 1.412 & 0.809 & 1.091 \\
\hline 4 & & 0.036 & 10 & 8681 & 4823 & 6566 & 0.868 & 0.482 & 0.657 \\
\hline 5 & \multirow[t]{4}{*}{20000} & 0.36 & 3.16 & 41580 & 34520 & 117300 & 2.079 & 1.726 & 5.863 \\
\hline 6 & & 0.18 & 4.47 & 29720 & 20530 & 35580 & 1.486 & 1.027 & 1.779 \\
\hline 7 & & 0.09 & 6.33 & 20260 & 14540 & 21950 & 1.013 & 0.727 & 1.097 \\
\hline 8 & & 0.036 & 10 & 12130 & 8652 & 13150 & 0.606 & 0.433 & 0.657 \\
\hline 9 & \multirow[t]{4}{*}{40000} & 0.36 & 3.16 & 67220 & 63250 & 222000 & 1.681 & 1.581 & 5.552 \\
\hline 10 & & 0.18 & 4.47 & 43280 & 36680 & 71430 & 1.082 & 0.917 & 1.786 \\
\hline 11 & & 0.09 & 6.33 & 28980 & 23950 & 44230 & 0.725 & 0.599 & 1.106 \\
\hline 12 & & 0.036 & 10 & 17150 & 14190 & 26750 & 0.429 & 0.355 & 0.669 \\
\hline 13 & \multirow[t]{4}{*}{80000} & 0.36 & 3.16 & 104000 & 115600 & 401900 & 1.3 & 1.445 & 5.023 \\
\hline 14 & & 0.18 & 4.47 & 60110 & 66670 & 142200 & 0.751 & 0.833 & 1.777 \\
\hline 15 & & 0.09 & 6.33 & 39530 & 41370 & 94910 & 0.494 & 0.517 & 1.186 \\
\hline 16 & & 0.036 & 10 & 23170 & 23860 & 54280 & 0.29 & 0.298 & 0.678 \\
\hline 17 & \multirow[t]{4}{*}{160000} & 0.36 & 3.16 & 156600 & 235100 & 718700 & 0.917 & 1.47 & 4.492 \\
\hline 18 & & 0.18 & 4.47 & 90490 & 113800 & 278000 & 0.566 & 0.711 & 1.738 \\
\hline 19 & & 0.09 & 6.33 & 55210 & 68590 & 199500 & 0.345 & 0.429 & 1.247 \\
\hline 20 & & 0.036 & 10 & 32200 & 37910 & 119300 & 0.201 & 0.237 & 0.746 \\
\hline 21 & \multirow[t]{4}{*}{180000} & 0.36 & 3.16 & 165800 & 262500 & 807600 & 0.921 & 1.458 & 4.487 \\
\hline 22 & & 0.18 & 4.47 & 95910 & 129300 & 309500 & 0.533 & 0.718 & 1.719 \\
\hline 23 & & 0.09 & 6.33 & 58600 & 75430 & 236200 & 0.326 & 0.419 & 1.312 \\
\hline 24 & & 0.036 & 10 & 33600 & 39180 & 136400 & 0.187 & 0.218 & 0.758 \\
\hline 25 & \multirow[t]{4}{*}{270000} & 0.36 & 3.16 & 178500 & 501600 & 1365000 & 0.661 & 1.858 & 5.055 \\
\hline 26 & & 0.18 & 4.47 & 113300 & 161100 & 554100 & 0.42 & 0.597 & 2.052 \\
\hline 27 & & 0.09 & 6.33 & 67520 & 103900 & 367900 & 0.25 & 0.385 & 1.363 \\
\hline 28 & & 0.036 & 10 & 37320 & 53890 & 213300 & 0.138 & 0.2 & 0.79 \\
\hline 29 & \multirow[t]{4}{*}{360000} & 0.36 & 3.16 & 245200 & 990500 & 2283000 & 0.681 & 2.758 & 6.342 \\
\hline 30 & & 0.18 & 4.47 & 125600 & 270300 & 764000 & 0.349 & 1.302 & 2.122 \\
\hline 31 & & 0.09 & 6.33 & 73570 & 129700 & 592000 & 0.204 & 0.36 & 1.647 \\
\hline 32 & & 0.036 & 10 & 41200 & 65800 & 359000 & 0.114 & 0.183 & 0.997 \\
\hline 33 & \multirow[t]{4}{*}{720000} & 0.36 & 3.16 & 391000 & 1145000 & 13180000 & 0.543 & 1.59 & 18.305 \\
\hline 34 & & 0.18 & 4.47 & 155300 & 937600 & 876000 & 0.216 & 1.302 & 1.217 \\
\hline 35 & & 0.09 & 6.33 & 88060 & 266400 & 13100000 & 0.122 & 0.37 & 18.19 \\
\hline 36 & & 0.036 & 10 & 63890 & 109600 & 13570000 & 0.089 & 0.152 & 18.85 \\
\hline 37 & \multirow[t]{4}{*}{1000000} & 0.36 & 3.16 & 576600 & 661000 & 210600000 & 0.577 & 0.661 & 20.596 \\
\hline 38 & & 0.18 & 4.47 & 236700 & 3673000 & 20320000 & 0.237 & 3.673 & 20.316 \\
\hline 39 & & 0.09 & 6.33 & 99790 & 420600 & 21200000 & 0.1 & 0.421 & 21.205 \\
\hline 40 & & 0.036 & 10 & 50000 & 144300 & 21220000 & 0.05 & 0.144 & 21.21 \\
\hline
\end{tabular}




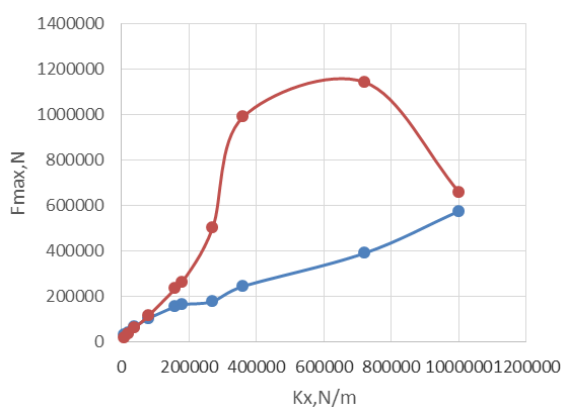

Fig. 4. Dependence $F_{\max }-k_{x}$ for the values $a=0.36 \mathrm{~m}, p=3.16 \mathrm{rad} / \mathrm{s}$

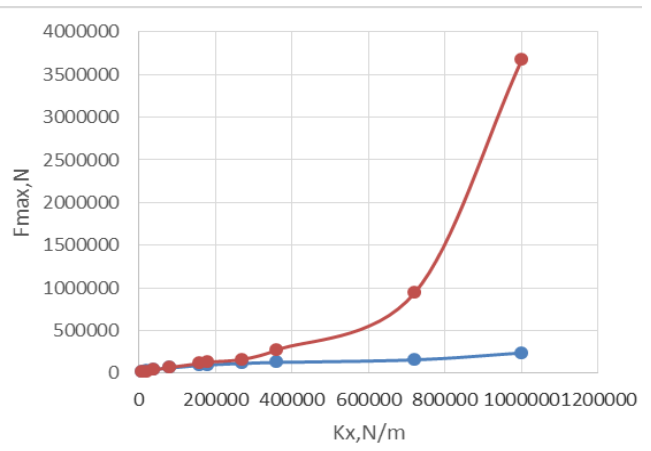

Fig. 5. Dependence $F_{\max }-k_{x}$ for the values $a=0.18 \mathrm{~m}, p=4.47 \mathrm{rad} / \mathrm{s}$

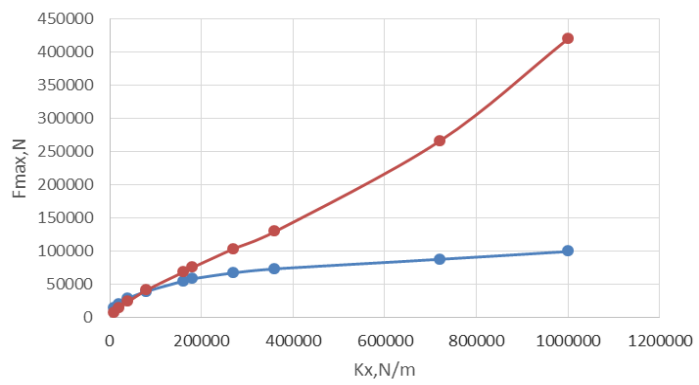

Fig. 6. Dependence $F_{\max }-k_{x}$ for the values $a=0.09 \mathrm{~m}, p=6.33 \mathrm{rad} / \mathrm{s}$

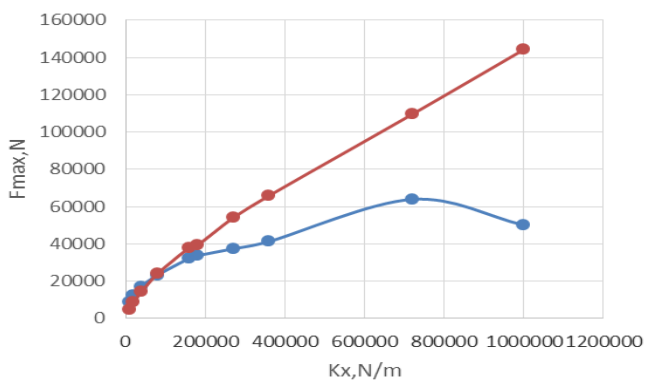

Fig. 7. Dependence $F_{\max }-k_{x}$ for the values $a=0.036 \mathrm{~m}, p=10 \mathrm{rad} / \mathrm{s}$ 
The upper graph is built for the cantilever structure, and the lower one is for the suspension version. The Table 1 and Figures 4-7 demonstrate that the strains in the suspension scheme are significantly less than the forces in the cantilever scheme for the real range of stiffness of the bearing frame. For the very small (unrealistic) values of stiffness of the bearing frame in the cantilever structure are less than the strains in the suspension version. However, these are purely theoretical values, because such stiffness coefficients of the frame displacements of its top are more than $1.5 \mathrm{~m}$, which certainly are not acceptable in practice. Furthermore, the real stiffness of the bearing column in Figure 1 for the existing Rozhnovsky water tower is equal to $176600 \mathrm{~N} / \mathrm{m}$. This coefficient is easily obtained by applying to a cantilever rod of height $21.25 \mathrm{~m}$ (see Figure 1) the horizontal force and by determining the displacement of its end (top). The stiffness of the bearing frame for the suspension structure (see Figure 2) can be naturally adjusted by adding braces and spacers between the columns of the supporting frame. It is easy to check that this is the way to adjust the stiffness within very large limits.

By the real limits of the stiffness of the bearing frame (for the studied case with the Rozhnovsky water tower) the value of the stiffness coefficient $k_{x}$ can be considered from 100000 to $600000 \mathrm{~N} / \mathrm{m}$. As can be seen from Figures 4-7 and from the Table 1, the dynamic forces and displacements in the suspension version of the structure (Figure 3, b) for such stiffness, are significantly less than the forces in the cantilever (traditional) version.

Finally, it should be noted that the strains in the suspension scheme were determined by means of theoretical mechanics on the proposals of the authors [2-4]. Strains in the cantilever structure (Figure 3, a and Figure 3, c) are also determined using the Lagrange equations of the second kind.

The advantage of the proposed technique for seismic protection, in addition to a significant reduction of dynamic forces (up to several times for different frequencies and amplitudes of the ground vibrations) is the ability to control the forces depending on the parameters of the earthquake. For example, additional dampers (springs) can be inserted into the bearing frame as shown in Figure 8.

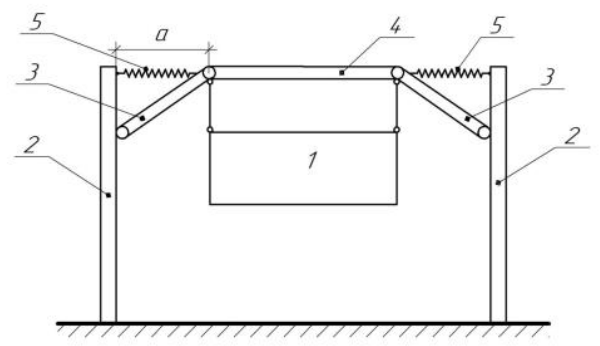

Fig. 8. Scheme of inserting the additional springs in the frame structure: 1 - suspension building (structure); 2 - columns of the bearing frame; 3, 4-elements of the hinge system; 5-springs (dampers)

In such a construction, the elements 3 and 4 in Figure 8 are connected to each other and to the columns of the bearing frame by hinges. It results in a movable scheme, the horizontal displacement of which is limited to the two sides of the springs ( 5 in Figure 8). The stiffness of the spring should be chosen from the following considerations. With a slight oscillation amplitude of the base displacement of the point of suspension of the building (structure) will mainly consist of displacements of the springs 5 , having less stiffness than the stiffness of the bearing frame. At the same time, the horizontal forces on the bearing frame will be small. At large amplitudes of vibrations of the base, the amplitude of the vibration of the suspension point increases (the value of $X_{\max }$ in the Table 1). Meanwhile, the spring can be completely compressed and additional horizontal displacements will already depend on the stiffness of 
the bearing frame. Thus, for the values of $X_{\max }$ in the Table 1, greater than the value of $a$ in Figure 8 , the stiffness at the suspension point of the building (structure) will be increased. Having the characteristics of the structure of the bearing frame, the calculation data (similar to the Table 1 and Figure 4-7), the required stiffness of both the bearing frame and the spring can be naturally determined. In such a construction at small amplitudes and large frequencies of the ground oscillations little strains will develop. At large amplitudes of the ground vibrations, the strains will increase and will be transmitted to the bearing frame.

The stiffness of the springs and the bearing frame can be chosen from the condition of the minimal displacements and the minimum possible dynamic forces of the construction.

Lastly, it should be noted that the suspension structure is applicable not only for the construction of the considered type, but also for any other structure, as well as both singlestorey and multi-storey buildings. Preliminary calculations of such structures using Lagrange Equations of the second kind do not differ significantly from the calculation of the structure given in this paper. It should also be pointed that the forces and vibration amplitude of the suspension structure (building) depend on the length of the suspension thread (see Figure 2). By adjusting this length certain desired results can also be achieved.

\section{Conclusions and prospects of research}

The possible replacement of the cantilever bearing scheme from the cantilever to the suspension one has been demonstrated on the example of the water tower. It is illustrated that the dynamic forces in the suspension scheme are significantly smaller than in the cantilever (existing) version. It is also proved that the forces depend both on the amplitude with frequency of the ground vibrations and on the stiffness $k_{x}$ of the bearing frame in the horizontal direction. The paper provides a design scheme with introduction of additional springs, which allow adjusting strains for the structure under seismic effects.

In the future, it is expected to improve the design of various suspension buildings and structures and the ways to adjust the forces depending on the frequency and amplitude of the vibration of the bases.

\section{References}

1. T. Azizov, Design of the earthquake-resistant buildings [Konstrukciya sejsmichno stijkoï budivli]. Patent for the useful model Nr 54247. Ukraine., (n.d.).

2. T. Azizov, and N. Jurkowska, Improving the design of the earthquake-proof suspension building / // (2018). DOI: 10.1051/e3sconf/20183601001, in: E3S Web Conf. 3601001 BIG 2018 - 4th NSCEIM, Krakow, 2018. doi:10.1051/e3sconf/20183601001.

3. T. Azizov, Dynamic design scheme of suspended seismically safe buildings, in: Sci. Eur., 2017: pp. 83-88.

4. Y.I. Nemchinov, Seismic resistance of buildings and structures [Sejsmostojkost' zdanij i sooruzhenij], Kiev, 2008.

5. M.G. Castellano, and S. Infanti, Recent applications of Italian anti-seismic devices, Earthq. Resist. Eng. Struct. / WIT Trans. Built Environ. Vol 104 (2009) 333-342. https://www.witpress.com/Secure/elibrary/papers/ERES09/ERES09031FU1.pdf.

6. CEN (2009) European code UNI EN 15129:2009. Anti-seismic devices, 2009.

7. V.S. Polyakov, L.S. Kilimnik, and A.V. CHerkashin, Modern methods for building protection [Sovremennye metody sejsmozashchity zdanij], Strojizdat, M., 1989.

8. V.N. Gordeev, V.A. Lantuh-Lyashchenko, A.I. Pashinskij, and et al., Loads and impacts on buildings and structures [Nagruzki i vozdejstv. na zdaniya i sooruzheniya], M., 2006. 